\title{
ONLINE COMMUNITIES: \\ RESEARCHING SOCIABILITY AND USABILITY IN HARD TO REACH POPULATIONS
}

\author{
Jenny Preece, Dean \\ College of Information Studies \\ University of Maryland \\ 4105E Hornbake Building, South Wing \\ College Park \\ Maryland, MD 20742, USA \\ preece@umd.edu
}

\section{ABSTRACT OVERVIEW}

\begin{abstract}
Thousands of social gatherings - online communities - occur via ICTs across the Internet. They use listservers, bulletin boards, instant messaging, blogs, social network and meeting facilitation systems and purpose-build platforms. Each community is the product of a complex set of interacting variables. Some of these variables come from usability of the software but social factors have a strong influence. Direct cause and effect relationships are often difficult to tease out and identifying criteria for successful online communities can be difficult. Furthermore several disciplines own this topic, each with its own theories, research methods, community of researchers and publication outlets. This is good for multidisciplinary research but it can be challenging. In this paper I discuss two research projects. Each focuses on community populations that are hard to reach. The first analyses why people do not actively participate in online discussions, i.e., lurk. The second is a new project to develop cross-cultural online book communities for children across the world who do not speak each other's languages. I present the key findings from each project and suggest ways of working with these hard to reach populations.
\end{abstract}

\section{Keywords}

Online community, networked community, ICT, social computing, usability, sociability, lurking, children, digital library

\section{INTRODUCTION}

Online communities are sources of information, support, entertainment and places to 'hang-out' and socialize for millions of people. These communities support patients coping with diseases, students discussing homework projects, hobbyists pursuing their passions, and teens chatting about their lives. Scholars use them to track academic topics, lawyers seek legal information, and professionals exchange business knowledge. A variety of software facilitates information exchange and communication including listservers, bulletin boards, instant messaging, blogs, social network and meeting facilitation systems and purpose-build platforms. These communities are known as 'Communities of Practice' (COPs) and 'Communities of Interest' (COIs) depending on their purposes. However, the term 'online community' is controversial for a number of reasons; not least because most online communities also have physical off-line components. For example, many online communities start as face-to-face communities before going online. Others start online and then subgroups realize that they live near enough to meet face-to-face.

Some efforts to define 'online community' encourage deeper understanding. For example, Wenger says that online communities comprise "people with a shared interest who engage in collective learning that creates bonds between them" (Wenger, 1998). Here the emphasis is on the role of shared interest in bringing people together. Learning promotes bonds that hold people together in the 
community. Depending on the nature of these bonds they can give rise to weak-tie and strong-tie communities (Granovetter, 1973). Each of us belongs to tens if not hundreds of weak-tie communities; email lists to which people subscribe can be thought of as weak-tie communities (Wellman, 1997). Weak-tie communities are wonderful for disseminating information. In contrast strong ties are harder to come-by. These are the people to whom we turn in times of real need, for a loan, a ride to the hospital, or to pick up your child from school when an important meeting is running over-time. We can further define a community by how people take and give back, that is, by reciprocity, or by the amount of trust reported by its members, or by networks of members' relationships.

Communities are often described by their focus of interest. While every community, like every person has its own characteristics or personality, communities drawn together by similar interests tend to be more similar than those drawn together by widely different interests. Online health communities differ from education communities, and from religious and political communities (Maloney-Krichmar and Preece, 2004 in press; Preece et al., 2003; 2004). Furthermore, many online communities share members with other communities that meet in other online spaces or off-line (Maloney-Krichmar and Preece, 2004 in press). Technically-oriented researchers tend to describe online communities in terms of their supporting technology; for example, a bulletin board community, an instant messaging (IM) community (Preece, 2000). We know that the nature of the social space provided by technology impacts community activity. Small differences between platforms can strongly influence social interaction. For example, personal information presented in pre-defined tabular format creates different perceptions from free-form descriptions.

Another way of thinking about community is from an operational perspective. An online community is "a group of people with a common purpose whose interaction is mediated and supported by computer systems, and governed by formal and informal policies" (Preece, 2000; 2004). Of course, when we delve beneath the surface of the four highlighted components - people, purpose, computer systems and policies - we see a much more complex set of attributes. People have identities that are determined by how and what they reveal about themselves online, which may be influenced by the design of the software, their expertise in using it or by something as fundamental as personality and motivation. People's skills and expertise contribute to their reputations that, in turn, influence how they behave online and how others perceive them, trust them, cooperate or challenge them (Preece, 2004). Using the "people, purposes and policies" components provides "handles" for understanding sociability, which can be mapped to usability design (Preece 2000; de Souza and Preece, 2004).

Online community researchers experience challenges that are well-known in human-computer interaction (HCI) research (Preece, Rogers, Sharp, 2002). For example, how do you get to know your users? Sometimes these problems are tricky in online communities as the two example studies reported below indicate. The goal of the first study was to get lurkers to speak out about why they don't actively participate so that community developers and managers can develop strategies to encourage them to participate when appropriate. The second study investigates ways of supporting community among children aged 7-11 from different cultures who may not speak the same language.

\section{PROJECT 1: WHY DON'T PEOPLE PARTICIPATE IN ONLINE} DISCUSSIONS?

New posts raising questions, giving answers or offering support, jokes and other comments encourage vibrant online discussion. If there is no new content community members will leave and seek to get their needs satisfied somewhere else. This was particularly evident during the dot.com era. Business entrepreneurs thought that they could add a bulletin board to their e-commerce site and that this "community" would draw-in customers and expand their sales. They were wrong. Adding 
communications software is not the same as creating an online community. Communities evolve nurtured by their members and leaders.

Some questions that intrigue commercial web developers and online community researchers are: what added value do online communities bring? Why do so many people prefer not to participate publicly (i.e., lurk)? How can we get people to actively contribute? Our research has investigated this question from a variety of perspectives (Andrews et al., 2003; Nonnecke et al., 2004; 2004a; 2004b; Preece et al, 2004). We know that lurking varies across different kinds of communities (Nonnecke and Preece, 2000) and that the number of lurkers is influenced by community size, moderation style, and software support, among other things.

From an online survey that generated 1188 responses from posters and lurkers from 375 MSN bulletin board communities, 219 lurkers spoke out about their reasons for not posting. We know from this study that while lurkers do not participate publicly, they did seek answers to questions. However, lurkers' satisfaction with their community experience is lower than those who post. Data from 19 checkbox items and over 490 open-ended responses were analysed in order to identify the main reasons why lurkers lurk. The reasons given were categorized under five types: (i) being able to get what they needed without having to post; (ii) needing to find out more about the group before participating; (iii) thinking that by not posting they were being helpful and not cluttering-up the conversation; (iv) not being able to make the software work (i.e., poor usability); and (v) not liking the group dynamics of the community (Preece et al, 2004).

While some lurkers can be thought of as free-riders who take with out reciprocating (Smith and Kollock, 1999), the vast majority lurk for other reasons, some of which are altruistic. By far the largest number of lurkers were unaware about the unsociable impact of their behaviour on others. From these findings it is clear that there are many ways that might improve online community experiences for both posters and lurkers. Some solutions require improved software and better tools, but better moderation practices and strategies for facilitating social interaction are needed, particularly for welcoming newcomers and during the early life of online communities.

Doing this research has also engaged us in finding solutions to a variety of challenges concerned with reading this 'hard-to-reach' user population. First we needed an operational definition of "lurking". Second, lurkers are by definition people who do not reveal themselves, so we had to find ways of getting lurkers to respond to our survey. Third, getting a representative sample from the unbounded and constantly changing populations in Internet communities is challenging (Andrews et al., 2003). In addition there are ethical issues associated with research on open Internet communities, particularly patient support communities, so getting IRB approval took time. We then experienced harassment from a small but vigorous group of sports community participants who tried to hack our server twice and sent obscene messages to our research assistant.

\section{PROJECT 2: INTERNATIONAL CHILDREN'S DIGITAL LIBRARY BOOK COMMUNITIES}

The second project is quite different. In this project we are researching and developing software to support online communities for children who access the International Children's Digital Library (ICDL) (Druin, 2002; Druin, 2004 in press). These children are geographically scattered across the world and the goal of this project is to support communicative exchanges that include games, story telling, chatting with friends, collaborating on projects and doing history, geography, math and reading. The children come from different countries and most do not speak the same language as the children that they meet online. Nor do they share the same culture. Indeed, another important goal of this research is foster cross-cultural understanding and tolerance.

The International Children's Digital Library Communities (ICDLcommunities) project extends the work of Allison Druin's and Ben Bederson's ICDL team. The project team includes specialists from AJIS Special Issue 
information studies, computer science, education, art and psychology and children aged 7-11 working together to build a digital library. The goal of their project is to put at least 100 children's books online for each of 100 countries across the world. In all there will be over 10,000 carefully selected children's books in the ICDL. Each book will be presented in the original language in which was written.

Understanding the technical, educational, recreational and learning needs of young children requires different techniques from those traditionally used with adults. Consequently, Allison Druin and her team have devoted considerable effort to developing appropriate techniques. They successfully use an intergenerational design methodology in which children and adults work together (Druin, 2002). This methodology has two broad components. A form of contextual inquiry enables the team to explore the design space, followed by participatory design in which the children and adults invent new designs for reviewing and testing. Working with children in this way involves negotiating new power structures in which the ideas and skills of both children and adults are respected. Different approaches to knowledge elicitation are also needed. Children like to use crayons and pens to draw their ideas. Glue, scissors, colored paper and various other artefacts are also useful for making models. This approach contrasts strongly with that of most adults who write, construct tables and other complex representations to describe their ideas.

The online ICDLCommunities project will enable children's communities to develop around the book collection. Children will talk about the books that they read online, create their own books and create and share their own stories aided by teachers and parents. Using the intergenerational design methods mentioned above, we are working with children to understand their community needs. What do they like to do online? How children engage with other children using technology? What do they talk about? What kinds of activities motivate the children? We know that for children's technology to be successful it must engage them, put them in control and give them appropriate feedback to support their social engagement with peers (Druin, 1999; Druin and Inkpen, 2001; Bruckman and Bandlow, 2002).

An added and non-trivial challenge for developing children's cross cultural book communities is that the children will meet others who do not speak their language. Already we are exploring prototype tools that will enable children to make their own drawings, develop picture dictionaries, exchange messages (mostly in the form of drawings or drawings that have been labelled), ask and answer questions. There are many challenges but to our surprise lack of a common language is not the most serious. Understanding each other becomes a game. It is fun to guess what the other children's pictures are about.

As well as having to develop new ways of understanding this 'hard-to-reach' user group of international children, we are also identifying issues that are known to be important in adult's online communities. For example, early on our Hungarian children's team asked to send photos of themselves to the American children's team. They were intrigued to see what the other children look like, how they use technology, what they do at school, what kind of sports they play, which holidays they celebrate, and what kinds of foods and candies they like. Identity and culture are important both collectively for the community and for individual children, just as they are for adults.

\section{CONCLUSIONS: SOME LESSONS LEARNED}

The findings from these projects suggest some sociability and usability principles for designing successful online communities and techniques for reaching 'hard-to-reach' user populations. These are summarized in the following ten suggestions for improving sociability and usability in online communities. 
10 Sociability and usability suggestions

- Enable communication tasks needs to be motivating and meaningful for participants (particularly for children)

- Devise software, moderator and community-run strategies for encouraging online participation (e.g., mentoring, tours, meeting areas for new-comers)

- Make participants aware of norms and responsibilities (particularly the need to contribute as well as take)

- Reward contributions and service to the community

- Provide reliable software (reliability wins over state-of-the art with many COI participants)

- Provide 24/7 access (particularly for support communities)

- Make the community's purpose clear (descriptive name, purpose statement, window onto the communication)

- Make communication software obvious (do not expect users to notice a link hidden in text and other links, provide a clear link or window onto the communication)

- Support online identity and development of trust and empathy (allow people to describe or show themselves through stories and pictures)

- Devise ways to make children's online activities as safe as possible (e.g., engage parents and teachers)

The 'take away' message from both research studies is that "while usability is always important it is not sufficient. We must pay careful attention to sociability too". Doing community-base research may require us to expand old techniques and develop new ones so that we can reach participants in "hard to reach" community populations. In our studies we had to (i) operationalize slippery concepts (e.g., lurking defined so that it was measurable); (2) adapt sampling techniques to be as rigorous as possible for researching unbounded Internet populations; and (3) develop community-centered participatory design methodologies for working with children from different cultural and language groups across the world.

\section{REFERENCES}

Andrews, D., Nonnecke, B., Preece, J. (2003) Electronic survey methodology: A case study in reaching hard to involve Internet Users. International Journal of Human-Computer Interaction. 16, 2, 185-210.

Bruckman, A. and Bandlow, A. (2002). HCI for Kids. In J. Jacko and A. Sears (Eds.) Handbook of Human-Computer Interaction. Hillsdale, NJ: Lawrence Earlbaum Associates.

De Souza, C., S., Preece, J. (2004) A framework for analyzing and understanding online communities. Interacting with Computers, The Interdisciplinary Journal of HumanComputer Interaction, 16, 3, 579-610.

Druin, A. (2002). The role of children in the design of new technology. Behaviour and Information Technology, 21(1), 1-25.(Tech Report version at: $\mathrm{ftp}: / / \mathrm{ftp} . c s . u m d . e d u / p u b / h c i l / R e p o r t s-A b s t r a c t s-B i b l i o g r a p h y / 99-23 \mathrm{html} / 99-23 . p d f)$

Druin, A. (Ed.). (1999) The design of children's technology. San Francisco, CA: Morgan Kaufmann. (Book at: http://www.umiacs.umd.edu/ allisond/books.html)

Druin, A. (In Press). What children can teach us: Developing digital libraries for children. Library Quarterly. (Tech Report version at: ftp://ftp.cs.umd.edu/pub/hcil/Reports-AbstractsBibliography/2003-39html/2003-39.pdf) 
Druin, A. and Inkpen, K. (2001) When are personal technologies for children. Personal Technologies, 5, 3, 191-194.

Granovetter, M. (1973) The strength of weak ties. American Journal of Sociology, 78,1360-1380.

Maloney-Krichmar, D. and Preece, J. (2004) A multilevel analysis of sociability, usability and community dynamics in an online health community (accepted, Transactions on HumanComputer Interaction)

Nonnecke, B. and Preece, J. (2000) Lurker demographics: Counting the silent. Proceedings of ACM CHI'2000, Hague, The Netherlands, 73-80.

Nonnecke, B., Andrews, D., Preece, J. (2004) Online Lurking: Current and past. Association of Internet Researchers (AoIR) Conference, Brighton, UK, September.

Nonnecke, B., Preece, J., Andrews, D. (2004a) Lurking and public participation in discretionary online communities. (accepted Electronic Commerce Research Journal.)

Nonnecke, B., Preece, J., Andrews, D., Voutour, R. (2004b) Online lurkers tell why. American Conference on Information Systems. (AMCIS) New York, August 5-8.

Preece, J. (2000) Online Communities: Designing Usability, Supporting Sociability. Chichester, UK: John Wiley \& Sons. www.ifsm.umbc.edu/onlinecommunities

Preece, J. (2004) Etiquette Online: From nice to necessary. Communications of the ACM, 47, 4, $56-61$

Preece, J., Abras, C., Maloney-Krichmar, D. (2004) Designing and Evaluating Online Communities: Research Speaks to Emerging Practice. International Journal of Web-based Communities. 1, $1,2-18$.

Preece, J., Maloney-Krichmar, D. and Abras, C. (2003) History of Online Communities In Karen Christensen \& David Levinson (Eds.), Encyclopedia of Community: From Village to Virtual World. Thousand Oaks: Sage Publications, 1023-1027.

Preece, J., Nonnecke, B., Andrews, D. (2004) The Top Five Reasons for Lurking: Improving Community Experiences for Everyone. Computers in Human Behavior. 20, 2, 201-223.

Preece, J., Rogers, Y. \& Sharp, H. (2002) Interaction Design: Beyond Human-Computer Interaction. New York, NY: John Wiley \& Sons. www.id-book.com

Smith, M. and Kollock, P. (1999) Communities in Cyberspace. London: Routledge.

Wellman, B. (1997) An electronic group is virtually a social network. In S. Kiesler (Ed.) Culture of the Internet. Mahwah, NJ: Lawrence Earlbaum Associates, 179-205.

Wenger, E. (1998) Communities of Practice. Cambridge, UK: Cambridge University Press.

\section{ACKNOWLEDGEMENTS}

I thank my colleagues from the community participation project: Dorine Andrews, Blair Nonnecke, Russell, Voutour and the International Children's Digital Library Online Communties project team: Allison Druin, Aaron, Elkiss, Anita Komladi, Philip Resnik, Enrique Stanziola, Roya Swartz, Lingling Zhang. NSF (Grant No: NSF 0328823) is supporting the International Children's Digital Library Online Communties project and the community participation project is partially supported by Microsoft Research and partially by University of Maryland Baltimore County.

\section{COPYRIGHT}

Jenny Preece (C) 2004. The authors assign to OZCHI and educational and non-profit institutions a non-exclusive licence to use this document for personal use and in courses of instruction provided that the article is used in full and this copyright statement is reproduced. The authors also grant a non-exclusive licence to OZCHI to publish this document in full in the Conference Papers and 
Proceedings. Those documents may be published on the World Wide Web, CD-ROM, in printed form, and on mirror sites on the World Wide Web. Any other usage is prohibited without the express permission of the authors. 